\title{
Adherence Factors Affecting Kidney Transplant Recipient among Patients on Maintenance Haemodialysis in Côte d'Ivoire
}

\author{
Delphine Amélie Lagou1,2*, Albert Pessa Coulibaly ${ }^{1}$, Luc Nigue ${ }^{3}$, Weu Mélanie Tiaa,2, \\ Monlet Cyr Guei ${ }^{1,2}$, Mohamed Ibrahim Alex Moudachirou ${ }^{1}$, \\ Kan Clément Ackoundou-N'Guessan1,2, Daze Apollinaire Gnionsahe ${ }^{1,2}$
}

\author{
${ }^{1}$ Nephrology Department, University Teaching Hospital of Yopougon, Abidjan, Côte d'Ivoire \\ ${ }^{2}$ Uro-Nephrology Department, Medical Science Department, Félix Houphouët Boigny University, Abidjan, Côte d'Ivoire \\ ${ }^{3}$ Department of Public Health and Medical Informatics, Medical Science Department, Félix Houphouët Boigny University, \\ Abidjan, Côte d'Ivoire \\ Email: ^amelielagou@gmail.com
}

How to cite this paper: Lagou, D.A., Coulibaly, A.P., Nigue, L., Tia, W.M., Guei, M.C., Moudachirou, M.I.A., Ackoundou-N'Guessan, K.C. and Gnionsahe, D.A. (2017) Adherence Factors Affecting Kidney Transplant Recipient among Patients on Maintenance Haemodialysis in Côte d'Ivoire. Open Journal of Nephrology, 7, 69-79.

https://doi.org/10.4236/ojneph.2017.73009

Received: July 11, 2017

Accepted: September 25, 2017

Published: September 28, 2017

Copyright (๑) 2017 by authors and Scientific Research Publishing Inc. This work is licensed under the Creative Commons Attribution International License (CC BY 4.0).

http://creativecommons.org/licenses/by/4.0/ (c) (i) Open Access

\begin{abstract}
Background: Kidney Transplantation is the best treatment for patients in end stage renal disease. It's a new therapeutic approach for such patients in Cote d'Ivoire which is expected to develop. Aim: Determine the adherence factors affecting kidney transplant recipient among patients on maintenance haemodialysis in Cote d'Ivoire and point out possible obstacles to the development of this new practice in the country. Patients and Methods: This was a cross-sectional study carried out from May to June 2016 in the Haemodialysis Centres of Abidjan. Any patient aged $\geq 18$ years, on haemodialysis for at least 6 months, who signed the inform consent were subjected to a questionnaire. None of the respondents had been transplanted. The subjects addressed in the document were sociocultural status, opinion related to kidney transplantation and willingness to be transplanted or not and the reasons. A statistical analysis was performed to determine factors associated with kidney transplantation desire. Results: We included 295 (71.53\% males) patients, with a mean age of $44.53 \pm 12.09$ years. Among this population, $36.61 \%$ had a higher level of education, $70.85 \%$ were Christians, $66.44 \%$ lived with partners, $56.61 \%$ had no income and $74.92 \%$ were treated in Public Health Centres. The median duration on dialysis was 34 months. A total of 287 (97.29\%) patients had already heard of kidney transplantation among which 149 (51.94\%) for the first time after initiation of haemodialysis. There was $231(78.31 \%)$ patients willing to be transplanted with only 91 (39.39\%) of them having a potential living donors. The main motivations were the desire to stop dialysis (52.38\%) and the search for a better quality of life (41.13\%). Among the 64 (21.69\%) patients unfa-
\end{abstract}


vourable to renal transplantation, $45.31 \%$ raised its higher cost compared to haemodialysis. Duration on haemodialysis ( $>34$ months) was significantly higher in patients willing to be transplanted compare to non-applicants $(51.95 \%$ versus $37.50 \%, \mathrm{p}<0.04)$. Factors associated with renal transplantation willingness were younger age ( $<45$ years $)(\mathrm{OR}=2.14 \mathrm{CI}$ : $1.12-4.06 \mathrm{p}=$ 0.02 ), longer median duration on dialysis ( $>34$ months) ( $\mathrm{OR}=2.12 \mathrm{CI}: 1.15$ $3.88 \mathrm{p}=0.01)$ and the Christian religion $(\mathrm{OR}=0.43 \mathrm{CI}: 0.20-0.92 \mathrm{p}=0.03)$. Conclusion: Almost all patients on maintenance haemodialysis were willing to be transplanted. However, the rate of living donor remains insufficient. For the non-seekers, the high cost of the process remains the main obstacle to kidney transplantation. Transplantation should be given more attention and political support economically by the Government to allow its development in Cote d'Ivoire.

\section{Keywords}

Kidney Transplantation, Adherence Factors, Haemodialysis, Côte d'Ivoire

\section{Introduction}

Chronic kidney disease is a global public health issue due to its steady spreading. In Côte d'Ivoire, a West Africa Country, the accurate prevalence of the disease is unknown. In 2001, based on hospital records which were not published, 46.12\% of patients admitted to nephrology services were suffering from chronic kidney disease. A study in an Internal Medicine Clinic located in Abidjan revealed a hospital incidence of $7.5 \%$ over 5 years (2004-2008) with $82.4 \%$ patients in end stage renal disease [1]. Most of the patients suffering from this disease are young people with a mean age of 38 years and the main causes are Hypertension and infectious diseases mainly HIV infection [2].

End stage renal disease patient survival requires renal replacement therapy such as kidney transplantation and dialysis. Kidney transplantation is the treatment of choice for patients with end-stage renal disease. It helps to improve the quality of life and increase patients' life expectancy compared to dialysis [3]. Unlike developed countries, kidney transplantation is not a common practice in Africa. Only North Africa countries and few sub-Sahara English-speaking countries (South Africa, Sudan and Kenya) perform kidney transplantation from a living kidney donor except South African which also performs it for cadaveric donors [4].

In Côte d'Ivoire, before the implementation of the law authorizing organs donation, several patients were transplanted abroad with sometimes disastrous consequences [5]. Indeed, mortality rate was high after the patient return due to financial issues, which made the medical follow-up a burden. It was therefore necessary to start local kidney transplantation from living donors, as performed in these African countries. Two years after the beginning of this activity in September 2012, ten (10) renal transplantations have been successfully performed 
despite numerous challenges in patient follow-up [6]. This activity, which is recent in Côte d'Ivoire, is expected to develop as in developed countries. The success of kidney transplantation program depends on several factors such as the accessibility and the adherence of the patients to the project [7]. Indeed, according to Vamos [8], patient interest in renal transplantation is a fundamental step in this process. We carried out this study to determine the adherence factors affecting kidney transplant recipient among patients on maintenance haemodialysis in Cote d'Ivoire and point out possible obstacles to the development of this new practice in the country.

\section{Patients and Methods}

\subsection{Population and Type of Study}

This was a multi-centre, cross-sectional study carried out from May to June 2016 and using a self-administered questionnaire for patients. This study concerned end-stage renal disease patients treated in the three majors Public and eight Private Haemodialysis Centre in the city of Abidjan which concentrate the largest number of haemodialysis centre and dialysis patients in Côte d'Ivoire. The chronic dialysis population in Abidjan was 418 patients at the time of the Study. Those who agreed to submit to the questionnaire were selected.

We included patients who were 18 years of age or more, on maintenance intermittent haemodialysis for at least 6 months and who have given their inform consent. We excluded previously transplanted patients with graft loss.

\subsection{Methods}

\subsubsection{Data Collection and Determination}

The inclusion of the patients was entirely done on a voluntary and anonymous basis. Verbal informed consent has been obtained from all participants. All these patients were informed on the objectives and the methods of the study. An individual information sheet with a number and an identification code was given to the patients.

All information gathered in this study was processed in accordance with the Code of Ethics.

Concerning the questionnaire, we developed a grid of questions with several items designed after a pre-test. A pilot study was conducted by the research team of 20 randomly selected patients to determine its clarity before validating the final questionnaire. For illiterate patients, the formulations in the local dialect have been selected and validated by the research team so as to minimize biases.

Patients should answer the questions in writing whether during dialysis session or at home. Illiterate patients could be assisted by the staff of the haemodialysis Centre (doctors and nurses) or by close relatives at home when filling in the questionnaire sheet. The completed files at home were reassessed before validation.

The questions were based on demographic (age, sex), sociocultural (marital 
status, religion, Intellectual level, patients' income) issues, opinion related to kidney transplantation (patients have ever heard of kidney transplantation, the period of information as regard the diagnosis of renal failure or the treatment on dialysis and the source of information), the desire to be transplanted or not and the reasons, and for kidney transplantation applicants the chance to get potential donor and the relationship with that person. These data were completed by the Haemodialysis health Centre physician as for the information related to the type of centre (Private or Public Health centres), the duration on haemodialysis, the initial nephropathy and associated co-morbidity.

A comparison between the seekers and non-seekers for kidney transplantation was based on demographic, socio-cultural and dialysis data (type of center and mean duration on dialysis) and these parameters were analyzed to determine the features that influence the demand for kidney transplantation.

\subsubsection{Statistical Analysis}

The results were expressed as means \pm standard deviation or median (interquartile rang) for parametric data and in percentage (\%) for non-parametric data. Comparison of averages was based on Student $t$ Test or the Kruskall-Wallis Test. The percentage comparison was carried out using Pearson's Chi-square test or Fisher exact test. The difference was considered as significant with a value of $\mathrm{p}<$ 0.05. A multivariate analysis was carried out using logistic regression method with a significance threshold of $5 \%$.

\section{Results}

Two hundred and ninety-five (295) haemodialysis patients were involved in the study. The general characteristics of the patients are summarized in Table 1. Male predominance was noticed with a sex ratio of 2.5:1. The mean age of patients was $44.53 \pm 12.09$ years $(19-75)$ and $55.25 \%$ of patients were under 45 years old. In this sample population, $36.61 \%$ had a higher level of education, 70.85\% were Christian, $66.44 \%$ were living with a partner, $56.61 \%$ had no income and $74.92 \%$ were treated in Public Dialysis Centres. The mean duration on dialysis was $48.9 \pm 37.7$ months $(8-258)$ with a median duration of 34 months (19 - 71.5). Almost two-thirds of the patients were on dialysis less than 5 years.

Almost all patients (287/97.29\%) had already heard of kidney transplantation and half of them (149/51.94\%) for the first time after being on dialysis. Their source of information on kidney transplantation was various. Patients found information themselves or from their relatives (51.57\%), and only $38.33 \%$ were informed by the nephrologist (Table 2).

The majority of patients (78.31\%) favoured renal transplantation (Table 2). The main reasons were the desire to stop dialysis (52.38\%) and the search for a better quality of life (41.13\%) (Table 3). Among these patients willing to be transplanted, only 91 (39.39\%) had a potential living donor. As for 77 patients (84.62\%), donors were relatives (1st or 2 nd degree) and we noticed non-related donors for 14 patients (spouse, friend). For the 64 patients (21.69\%) who did not 
Table 1. General data of haemodialysis patients.

\begin{tabular}{|c|c|}
\hline Data of haemodialysis patients & $\begin{array}{l}\text { Number of patients } \\
\text { (Frequency \%) }\end{array}$ \\
\hline \multicolumn{2}{|l|}{ Gender } \\
\hline Male/Female & $211(71.53 \%) / 84(28.47 \%)$ \\
\hline \multicolumn{2}{|l|}{ Age groups } \\
\hline 18 - 44 years & $163(55.25 \%)$ \\
\hline 45 - 64 years & $117(39.66 \%)$ \\
\hline 65 years and over & $15(5.08 \%)$ \\
\hline \multicolumn{2}{|l|}{ Education } \\
\hline Higher & $108(36.61 \%)$ \\
\hline Secondary & $115(38.98 \%)$ \\
\hline Primary & $40(13.56 \%)$ \\
\hline No schooling & $32(10.85 \%)$ \\
\hline \multicolumn{2}{|l|}{ Religion } \\
\hline Christian & $209(70.85 \%)$ \\
\hline Muslim & $60(20.34 \%)$ \\
\hline Others (African traditional worshipers, Buddhism...) & $26(8.81 \%)$ \\
\hline \multicolumn{2}{|l|}{ Marital status } \\
\hline couple (married, common law, couple) & $196(66.44 \%)$ \\
\hline Single (bachelor, widow, divorcee) & $99(33.56 \%)$ \\
\hline \multicolumn{2}{|l|}{ Financial situation } \\
\hline Income/No income & $128(43.39 \%) / 167(56.61 \%)$ \\
\hline \multicolumn{2}{|l|}{ Dialysis centre } \\
\hline Public health centre & $221(74.92 \%)$ \\
\hline Private health centre & $74(25.08 \%)$ \\
\hline \multicolumn{2}{|l|}{ Duration on dialysis } \\
\hline$<5$ years & $195(69.40 \%)$ \\
\hline $5-10$ years & $74(26.33 \%)$ \\
\hline$>10$ years & $12(4.27 \%)$ \\
\hline \multicolumn{2}{|l|}{ Initial Nephropathy } \\
\hline Vascular nephropathy & $135(45.76 \%)$ \\
\hline Glomerular nephropathy & $64(21.69 \%)$ \\
\hline \multicolumn{2}{|l|}{ (obstructive and malformative uropathy) } \\
\hline \multicolumn{2}{|l|}{ (autosomal dominant polycystic kidney disease) } \\
\hline Undetermined & $81(27.45 \%)$ \\
\hline \multicolumn{2}{|l|}{ Co-morbidities associated } \\
\hline Hypertension & $76(64.95 \%)$ \\
\hline Diabetes & $24(20.51 \%)$ \\
\hline HIV infection & $20(17.09 \%)$ \\
\hline Others & $15(12.82 \%)$ \\
\hline
\end{tabular}

agree for kidney transplantation, $45.31 \%$ found the cost higher than that of haemodialysis (Table 4).

When we compared the two categories of patients (kidney transplantation 
Table 2. Patients' opinions related to kidney transplantation.

\begin{tabular}{lc}
\hline \multicolumn{1}{c}{ Patients opinions related to kidney transplantation } & $\begin{array}{c}\text { Number of patients } \\
\text { (Frequency \%) }\end{array}$ \\
\hline $\begin{array}{l}\text { Have you ever heard about kidney transplantation? } \\
\text { Yes/No }\end{array}$ & $287(97.29 \%) / 8(2.71 \%)$ \\
When did you hear about it for the first time? & $123(42.86 \%)$ \\
Before the diagnosis of kidney disease & $15(5.23 \%)$ \\
Before being on dialysis & $149(51.94 \%)$ \\
after being on dialysis & \\
Who told you or how did you hear about kidney & $110(38.33 \%)$ \\
transplantation for the first time? & $73(25.44 \%)$ \\
Nephrologist & $75(26.13 \%)$ \\
Own initiatives (Media, Internet, school research) & $29(10.11 \%)$ \\
Relatives (parent, Friends) & \\
Others (nurse in haemodialysis service, other physician, other & \\
patients on dialysis) & \\
Are you willing to be transplanted? & $231(78.31 \%) / 64(21.69 \%)$ \\
\hline
\end{tabular}

Table 3. Motivations for kidney transplantation $(n=231)$.

\begin{tabular}{cc}
\hline Motivations for kidney transplantation & $\begin{array}{c}\text { Number of patients } \\
\text { (Frequency \%) }\end{array}$ \\
Stop dialysis & $121(52.38 \%)$ \\
To get a better quality of life & $8(3.46 \%)$ \\
Others (high cost of dialysis, availability of living donor) & $95(41.13 \%)$ \\
\hline
\end{tabular}

Table 4. Reasons for refusing kidney transplantation $(n=64)$.

\begin{tabular}{cc}
\hline Reasons for refusing kidney transplantation & $\begin{array}{c}\text { Number of patients } \\
\text { (Frequency \%) }\end{array}$ \\
Expecting miraculous healing & $29(45.31 \%)$ \\
Nigh cost of kidney transplantation compared to dialysis & $6(9.38 \%)$ \\
Fear of kidney rejection and side effects of immunosuppression & $4(6.25 \%)$ \\
$\begin{array}{c}\text { Others (lack of prospective living donors, older age, refuse } \\
\text { someone else's organ, fear of death during the surgery, opposition } \\
\text { of the family or the partner, religious/cultural beliefs) }\end{array}$ & $4(6.25 \%)$ \\
\hline
\end{tabular}

seeker and non-seeker), duration on haemodialysis is significantly higher in the first group $(51.95 \%$ versus $37.50 \%, \mathrm{p}<0.04)$ (Table 5). Following logistic regression analysis, factors related to kidney transplantation willingness were age $<45$ years $(\mathrm{OR}=2.14 \mathrm{CI}: 1.12-4.06 \mathrm{p}=0.02)$, median duration on dialysis $>34$ months $(\mathrm{OR}=2.12 \mathrm{CI}: 1.15-3.88 \mathrm{p}=0.01)$ and the Christian religion $(\mathrm{OR}=$ 0.43 IC: $0.20-0.92 \mathrm{p}=0.03)$ (Table 6). 
Table 5. Comparative characteristics between patients willing and those unwilling to undergo kidney transplant.

\begin{tabular}{|c|c|c|c|c|c|}
\hline \multirow{2}{*}{\multicolumn{2}{|c|}{ Characteristics of patients }} & \multicolumn{4}{|c|}{ Wants transplant } \\
\hline & & \multirow{3}{*}{$\begin{array}{c}\text { Total } \\
163(55.25 \%) \\
132(44.75 \%)\end{array}$} & \multirow{2}{*}{$\begin{array}{c}\text { Yes } \\
133(57.58 \%)\end{array}$} & \multirow{2}{*}{$\begin{array}{c}\text { No } \\
30(46.88 \%)\end{array}$} & \multirow{3}{*}{$\begin{array}{c}\text { p-value } \\
0.12\end{array}$} \\
\hline & $19-44$ & & & & \\
\hline Age (years) & $45-75$ & & $98(42.42 \%)$ & $34(53.13 \%)$ & \\
\hline & Mean & $44.53 \pm 12.1$ & $43.83 \pm 14$ & $47.06 \pm 14$ & 0.10 \\
\hline \multirow[t]{2}{*}{ Gender } & Male & $211(71.53 \%)$ & $169(73.16 \%)$ & $42(63.63 \%)$ & 0.23 \\
\hline & $\begin{array}{c}\text { Not } \\
\text { schooling }\end{array}$ & $32(10.85 \%)$ & $24(10.39 \%)$ & $08(12.50 \%)$ & \\
\hline \multirow[t]{3}{*}{ Education } & Primary & $40(13.56 \%)$ & $32(13.85 \%)$ & $08(12.50 \%)$ & 0.84 \\
\hline & Secondary & $115(38.98 \%)$ & $88(38.10 \%)$ & $27(42.19 \%)$ & \\
\hline & Higher & $108(36.61 \%)$ & $87(37.66 \%)$ & $21(32.81 \%)$ & \\
\hline \multirow[t]{2}{*}{ Marital status } & Couple & $196(66.44 \%)$ & $153(66.23 \%)$ & $43(67.19 \%)$ & 0.88 \\
\hline & Christian & $209(70.80 \%)$ & $157(75.12 \%)$ & $52(24.88 \%)$ & \\
\hline \multirow[t]{2}{*}{ Religion } & Muslim & $60(20.34 \%)$ & $51(85 \%)$ & $09(15 \%)$ & 0.11 \\
\hline & Others & $26(8.81 \%)$ & $23(88.46 \%)$ & $03(11.54 \%)$ & \\
\hline $\begin{array}{l}\text { Financial } \\
\text { situation }\end{array}$ & Income & $128(43.39 \%)$ & $100(43.29 \%)$ & $28(43.75 \%)$ & 0.94 \\
\hline $\begin{array}{c}\text { Duration on } \\
\text { dialysis }\end{array}$ & Median & 34 & 36 & 21 & 0.07 \\
\hline (months) & $\geq 34$ & $144(48.81 \%)$ & $120(51.95 \%)$ & $24(37.50 \%)$ & $0.04^{*}$ \\
\hline Dialysis centre & Public & $221(74.92 \%)$ & $172(74.46 \%)$ & $49(76.56 \%)$ & 0.87 \\
\hline
\end{tabular}

*Significant $\mathrm{p}$ value.

Table 6. Factors associated with kidney transplantation desire.

\begin{tabular}{ccc}
\hline Parameters & Odds ratio (CI 95\%) & p-value \\
\hline Age (<45 years) & $2.14(1.12-4.06)$ & $0.02^{*}$ \\
Gender (Male) & $1.21(0.58-2.52)$ & 0.59 \\
Marital status (couple) & $1.03(0.53-2.03)$ & 0.91 \\
Religion (Christian/Muslim and others) & $0.43(0.20-0.92)$ & $0.03^{*}$ \\
Education (Higher/Secondary/Primary/Not & $1.09(0.77-1.54)$ & 0.59 \\
schooling) & $1.03(0.49-2.16)$ & 0.92 \\
Financial situation (Income) & $0.99(0.48-2.05)$ & 0.99 \\
Dialysis centre (Public) & $2.12(1.15-3.88)$ & $\mathbf{0 . 0 1}$ \\
\hline Median duration on dialysis (>34 months) &
\end{tabular}

${ }^{*}$ Significant $\mathrm{p}$ value.

\section{Discussion}

Haemodialysis patients in Côte d'Ivoire are well aware of kidney transplantation and its benefits. The sources of information were various and only $38.33 \%$ of the patients had been informed by their nephrologists, and after being on dialysis for most of them. Some of these patients (78.31\%) have expressed their willingness 
to be transplanted. Based on studies, this rate varies from $34.9 \%$ to $76 \%$ [8]-[15] and is similar to that reported in other African countries such as Morocco [15]. The reasons mentioned were essentially the willing to stop dialysis and to improve the quality of life. The improvement of life quality has also been mentioned by patients in several studies [8] [9] [10] [15]. The lack of facilities for adequate haemodialysis in developing countries in general is a source of high rate of mortality and poor quality of life. Kidney transplantation therefore represents the hope of survival and an improvement of life quality. Among haemodialysis patients willing kidney transplantation, only about $40 \%$ had potential living donor, although this rate is higher in other studies [9] [14] [16]. This result contrasts with a study carried out in Côte d'Ivoire as a prelude to the kidney transplantation project, which identified a large number of potential living donors [17]. To increase the number of effective donors, accurate information and promotion of donation is needed, for, a study carried out in Côte d'Ivoire on the future of the living donors has shown that the risk related to kidney donation is weak after an average of 4 years follow-up [18] as reported in the literature. However, one should note that kidney disease patients are sometimes reluctant to ask for renal donation from a living person. In fact, only $34.2 \%$ of patients from minority group have made this step towards their relatives in the USA [13].

In our study the rate of patient rejecting kidney transplantation was estimated at $21.69 \%$. In other studies, this rate varies from $13.7 \%$ to $35 \%$ [10] [12] [19]. According to Pradel [20], the setting up of a patient education program for the promotion of kidney transplantation may be necessary to improve treatment compliance.

While the results of the western studies explain the rejection of kidney transplantation by the fear of the immunosuppression and uncertainty related to the development of the transplantation [10], or a previous personal or somebody else bad experience [21], our patients lay the emphasis upon the high cost of the transplantation. The high cost of kidney transplantation compared to dialysis was also mentioned by patients in other African countries [12] [15] [16], China [9] and in the African American community [11] of USA. According to Muller [4], one of the recurrent and significant barriers to kidney transplantation in Africa is its high cost and follow-up expenses, mainly long-term immunosuppressive therapy. For the particular case of Côte d'Ivoire, apart from the Public Health Centres where haemodialysis is subsidized by the Government for the benefit of many patients, kidney transplantation patient does not receive any subsidy from the State for the time being. Indeed, all of the process costs (donor/recipient pre-transplant examination, transplant surgery, immunosuppressive drugs, clinical consultation, para-clinical follow up) are totally paid by the patients and, unfortunately, most of them do not have an health insurance and there is no universal health insurance system in the country. The cost of kidney transplantation from the pre-transplant examination to the third month after the surgery is about 20,000 Dollars US. It is widely reported that if the cost of the 
transplantation equals the expenses of the dialysis during the first year, this cost declines and becomes one quarter or less of the dialysis charges [22]. Thus, it would be advantageous in these circumstances for the Government to invest more in kidney transplantation in Public Health Center instead of spending significant sum of money in a long lasting dialysis.

Unlike Buturovic-Ponikvar [19] who did not find any difference between seekers and non-seekers for Kidney transplantation, the younger age, the longer duration in dialysis, belonging to Christian religion were reasons for kidney transplantation in our study. The relative young age of applicants for kidney transplantation was also mentioned by other authors [10] [21]. Patients on dialysis for long period were willing to kidney transplantation. In developing countries, this may be explained by constraints related to haemodialysis. In fact these patients are psychologically affected and they do not support long-lasting palliative treatment. Even if the Christian religion was one of the factors for kidney transplantation willingness, it has been reported that the other religions, notably the Muslim religion is not reluctant to transplantation [23]. Our result may be affected by the fact that the study was carried out in the southern part of the country (Abidjan) which is dominated by Christian people.

\section{Conclusion}

Many patients on haemodialysis in Côte d'Ivoire are willing to undergo kidney transplantation. Most of them are young people, on long-lasting dialysis and from Christian religion. However, the rate of living donor remains insufficient. For the non-seekers, the high cost of the process remains the main obstacle to kidney transplantation. Promoting organ donation and the affordability of kidney transplantation through the involvement of the Government could help to reduce the cost and allow the transplantation development. Moreover, pre-dialysis patients and their family should be better informed by nephrologist on kidney transplantation.

\section{Limitations of the Study}

Although the study was multicenter, it did not take into account the 3 haemodialysis centers located in the others areas of Côte d'Ivoire (in the center and west). Which would have allowed us to have a larger population and avoid some bias in the results. Our study may be considered preliminary and we therefore suggest a national multicentre survey.

\section{Conflict of Interest}

None declared.

\section{References}

[1] Ouattara, B., Kra, O., Yao, H., Kadjo, K. and Niamkey, E.K. (2011) Characteristic of Chronic Renal Failure in Black Adults Patients Hospitalized in the Internal Medicine Department of Triechville University Hospital. Néphrologie \& Thérapeutique, 
7, 531-534. https://doi.org/10.1016/j.nephro.2011.03.009

[2] Ackoundou-N'guessan, K.C., Lagou, D.A, Tia, W.M., Gnionsahe, D.A. and Guei, M.C. (2011) Risk Factors for Chronic Renal Failure in Ivory Coast: A Prospective Study of 280 Patients. Saudi Journal of Kidney Disease and Transplantation, 22, 185-190

[3] Wolfe, R.A., Ashby, V.B., Milford, E.L., et al. (1999) Comparison of Mortality in All Patients on Dialysis, Patients on Dialysis Awaiting Transplantation and Recipients of a First Cadaveric Transplant. New England Journal of Medicine, 341, 1725-1730. https://doi.org/10.1056/NEJM199912023412303

[4] Muller, E. (2016) Transplantation in Africa-An Overview. Clinical Nephrology, 86, 90-95. https://doi.org/10.5414/CNP86S125

[5] Ackoundou-N'Guessan, C., Gnionsahe, D.A., Dekou, A.H., Tia, W.M., Guei, M. C. and Moudachirou, A.M. (2010) Outcomes of Renal Patients from the Ivory Coast Transplanted Abroad: Time of a Local Kidney Transplantation Program. Transplant Proceedings, 42, 3517-3520. https://doi.org/10.1016/j.transproceed.2010.08.048

[6] Ackoundou-N'guessan, C., Hoang, A.D., Ben Abdallah, T., Gnionsahe, D.A., Dollo, I., Ripoche, C. and et al. (2015) Living Kidney Donors Transplantation in a Resource-Limited Country: The Ivory Coast Experience. Transplant Proceedings, 47, 1580-1584. https://doi.org/10.1016/j.transproceed.2015.03.053

[7] Akoh, J.A. (2011) Renal Transplantation in Developing Countries. Saudi Journal of Kidney Disease and Transplantation, 22, 637-650.

[8] Vamos, E.P., Csepanyi, G., Zambo, M., Molnar, M.Z., Rethelyi, J., Kovacs, A. and et al. (2009) Sociodemographic Factors and Patient Perceptions Are Associated with Attitudes to Kidney Transplantation among Haemodialysis Patients. Nephrology Dialysis Transplantation, 24, 653-660. https://doi.org/10.1093/ndt/gfn660

[9] Qiao, B., Liu, L., Liu, J. and Xie, J. (2016) A Study on the Attitude toward Kidney Transplantation and Factors among Hemodialysis Patients in China. Transplant Proceedings, 48, 2601-2607. https://doi.org/10.1016/j.transproceed.2016.06.060

[10] Nizič-Kos, T., Ponikvar, A. and Buturović-Ponikvar, J. (2013) Reasons for Refusing Kidney Transplantation among Chronic Dialysis Patients. Therapeutic Apheresis and Dialysis, 17, 419-424. https://doi.org/10.1111/1744-9987.12090

[11] Ilori, T.O., Enofe, N., Oommen, A., Odewole, O., Ojo, A., Plantinga, L., et al. (2015) Factors Affecting Willingness to Receive a Kidney Transplant among Minority Patients at an Urban Safety-Net Hospital: A Cross-Sectional Survey. BMC Nephrolo$g y, 16,191$. https://doi.org/10.1186/s12882-015-0186-2

[12] Takure, A.O., Jinadu, Y.O., Adebayo, S.A., Shittu, O.B., Salako, B.L. and Kadiri, S. (2016) The Knowledge, Awareness, and Acceptability of Renal Transplantation among Patients with End-Stage Renal Disease in Ibadan, Nigeria. Saudi Journal of Kidney Disease and Transplantation, 27, 769-773. https://doi.org/10.4103/1319-2442.185241

[13] Gillespie, A., Hammer, H., Bass, S.B., Ouzienko, V., Obradovic, Z., Urbanski, M., et al. (2015) Attitudes towards Living Donor Kidney Transplantation among Urban African American Hemodialysis Patients: A Qualitative and Quantitative Analysis. Journal of Health Care for the Poor and Underserved, 26, 852-872. https://doi.org/10.1353/hpu.2015.0087

[14] Kabbali, N., Mikou, S., El Bardai, G., Tazi, N., Ezziani, M., Batta, F.Z., et al. (2014) Attitude of Hemodialysis Patients toward Renal Transplantation: A Moroccan Interregional Survey. Transplant Proceedings, 46, 328-331. 
[15] Laouad, I., Hbali, G., Mouhoub, R., Fadili, W., Lisri, M. and Kaitouni, A.I. (2011) Knowledge and Attitudes of Moroccan hemodialysis Patients toward Renal Transplantation: Did We Inform Our Patients Enough? Transplant Proceedings, 43, 445-447.

[16] Abdelwahab, H.H., Shigidi, M.M.T., Ibrahim, L.S. and El-Tohami, A.K. (2013) Barriers to Kidney Transplantation among Adult Sudanese Patients on Maintenance Haemodialysis in Dialysis Units in Khartoum State. Saudi Journal of Kidney Disease and Transplantation, 24, 1044-1049. https://doi.org/10.4103/1319-2442.118093

[17] Ackoundou-Nguessan, C., Gnionsahe, A., Kouame, E., Lagou, D., Tia, M., Sissoko, H., et al. (2007) Characteristics and of Potential Living Kidney Donors in Ivory Coast: A Survey Prior to a Project of Kidney Transplantation in French Black Africa. Néphrology \& Thérapeutique, 3, 456-460.

[18] Lagou, D.A., Ackoundou-N'guessan, K.C., Njapom, T.L., Sekongo, Y.M., Guei, C.M., Tia, M.W., et al. (2016) Characteristics and Outcome of Living Kidney Donors after Donation: A Report from Cote d'Ivoire. Saudi Journal of Kidney Disease and Transplantation, 27, 563-568. https://doi.org/10.4103/1319-2442.182400

[19] Buturović-Ponikvar, J., Gubenšek, J., Arnol, M., Bren, A., Kandus, A. and Ponikvar, R. (2011) Dialysis Patients Refusing Kidney Transplantation: Data from the Slovenian Renal Replacement Therapy Registry. Therapeutic Apheresis and Dialysis, 15, 245-249. https://doi.org/10.1111/j.1744-9987.2011.00945.x

[20] Pradel, F.G., Suwannaprom, P., Mullins, C.D., Sadler, J. and Bartlett, S.T. (2008) Short-Term Impact of an Educational Program Promoting Live Donor Kidney Transplantation in Dialysis Centers. Progress in Transplantation, 18, 263-272. https://doi.org/10.1177/152692480801800409

[21] Holley, J.L., McCauley, C., Doherty, B., Stackiewicz, L. and Johnson, J.P. (1996) Patients' Views in the Choice of Renal Transplant. Kidney International, 49, 494-498. https://doi.org/10.1038/ki.1996.70

[22] Durand-Zaleski, I., Combe, C. and Lang, P. (2007) International Study of Health Care Organization and Financing for End-Stage Renal Disease in France. International Journal of Health Care Finance and Economics, 7, 171-183. https://doi.org/10.1007/s10754-007-9025-8

[23] Oliver, M., Woywodt, A., Ahmed, A. and Saif, I. (2011) Organ Donation, Transplantation and Religion. Nephrology Dialysis Transplantation, 26, 437-444. https://doi.org/10.1093/ndt/gfq628 
Submit or recommend next manuscript to SCIRP and we will provide best service for you:

Accepting pre-submission inquiries through Email, Facebook, LinkedIn, Twitter, etc. A wide selection of journals (inclusive of 9 subjects, more than 200 journals)

Providing 24-hour high-quality service

User-friendly online submission system

Fair and swift peer-review system

Efficient typesetting and proofreading procedure

Display of the result of downloads and visits, as well as the number of cited articles Maximum dissemination of your research work

Submit your manuscript at: http://papersubmission.scirp.org/

Or contact ojneph@scirp.org 